
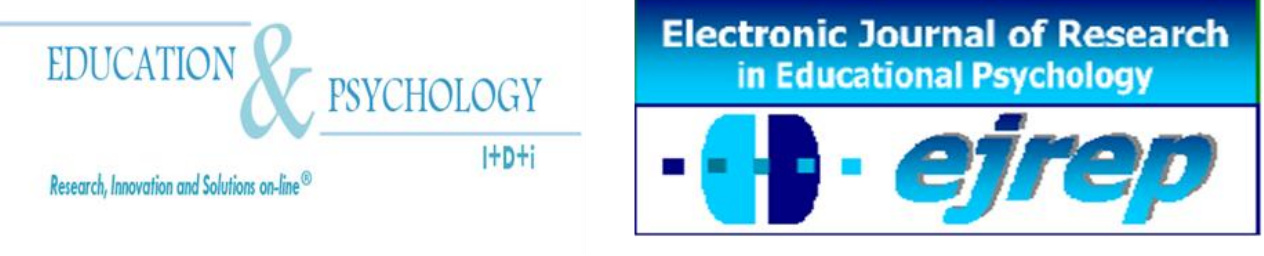

Editorial EOS

\title{
Evaluating the Effectiveness of Combined Reading Interventions on Improving Oral Reading Fluency of Students with Reading Disabilities
}

\section{Ruya Guzel-Ozmen}

\author{
${ }^{1}$ Special Education Department, Gazi University, \\ Ankara
}

Turkey

Correspondence: Ruya Guzel-Ozmen. Gazi Universitesi, Gazi Egitim Fakultesi, Teknikokullar 06500, Ankara. Turkey. E-mail: ruyaozmen@hotmail.com

(C) Education \& Psychology I+D+i and Editorial EOS (Spain) 


\section{Abstract}

Introduction. In recent years, brief experimental analysis (BEA) has emerged as an approach to identify the most effective instructional strategies needed to increase reading fluency before applying an intervention for extended periods of time. The purpose of this study was to investigate the effects of adding performance feedback to skill-based interventions on improving oral reading fluency of Turkish students with reading difficulties.

Method. Three different combined intervention packages were implemented in the study. Intervention packages included Listening Passage Preview and Repeated Reading (LPP+RR), Repeated Reading with Performance Feedback (RR+PF), and Listening Passage Preview and Repeated Reading with Performance Feedback (LPP+RR+PF). Brief experimental analysis was used to examine the effects of the intervention packages. Four elementary students were participated in the study. Participants were three fourth grade and one third grade students.

Results. Results demonstrated that two participants' reading fluency improved as a function of the $\mathrm{LPP}+\mathrm{RR}+\mathrm{PF}$ intervention and remaining two participants had the highest scores in the LPP+RR condition.

Conclusion. The results of this study extend the previous research by examining the effects of the combined intervention packages in improving reading fluency in Turkish language. Findings from the study suggest that assessing relative contribution of the strategies by using brief analysis can help determine the effective intervention packages for students in improving their reading fluency.

Keywords: brief experimental analysis, oral reading fluency, reading interventions, elementary students

Received: 06/23/11 Initial acceptance: 07/05/11 Final acceptance: 11/01/11 


\section{Evaluación de la eficacia de intervenciones conjuntas para mejorar la fluidez de lectura oral de alumnos con dificultades lectoras}

\section{Resumen}

Introducción. En los años recientes, ha surgido el análisis experimental breve (AEB) como una aproximación para identificar las estrategias instruccionales y las estrategias instruccionales más efectivas, necesarias para aumentar la fluidez de lectura, antes de aplicar una intervención para periodos de tiempo extendidos. El propósito de este estudio fue investigar los efectos de agregar la retroalimentación del desempeño a las intervenciones basadas en la habilidad mejorando la fluidez de lectura oral de los estudiantes Turcos con dificultades de lectura.

Método. Tres diferentes paquetes de intervención combinados fueron implementados en el estudio. Los paquetes de intervención incluyen Audición de Pasaje Preliminar y Lectura Repetida (LPP+RR), Lectura Repetida con Retroalimentación de Desempeño (RR+PF), y Audición de Pasaje Preliminar y Lectura Repetida con Retroalimentación de Desempeño $(\mathrm{LPP}+\mathrm{RR}+\mathrm{PF}) . \mathrm{El}$ análisis experimental breve fue usado para examinar los efectos de los paquetes de intervención. Cuatro estudiantes de elemental participaron el estudio. Los participantes fueron tres del grado cuarto y uno del tercer grado.

Resultados. Los resultados demostraron que la fluidez de lectura de dos participantes mejoraró como función de la intervención $\mathrm{LPP}+\mathrm{RR}+\mathrm{PF}$ y los otros dos participantes tuvieron los mayores puntajes en la condición LPP+RR.

Conclusión. Los resultados de este estudio apoyan la investigación previa, examinando los efectos de los paquetes de intervención combinados mejorando la fluidez en la lectura en la lengua Turca. Los hallazgos del estudio sugieren que la contribución relativa de evaluación de las estrategias usando el análisis breve puede determinar los paquetes de intervención efectivos para los estudiantes para mejorar su fluidez de lectura.

Palabras Claves: análisis experimental breve, fluidez de lectura oral, intervenciones de lectura, estudiantes de elemental 


\section{Introduction}

Reading is one of the first and most important academic skills taught to students for school success and accomplishments in the basic activities of daily life (Hopewell, McLaughlin, \& Derby, 2011; Roldán, Segura, \& Roldán, 2003). The characteristics of a language can impact students reading acquisition patterns (Oney \& Durgunoglu, 1997; Oney \& Goldman, 1984). Turkish, with its very systematic letter to phoneme correspondences, facilitates word recognition and spelling performances (Oney \& Goldman, 1984). Turkish students typically learn decoding by the 5th month of the first school year (YucesanDurgunoglu \& Oney, 2002) and students' reading typically becomes more fluent in the second grade (Erden, Kurdoglu, \& Uslu, 2002). Studies of beginning readers in Turkish suggested that the acquisition of decoding skills develops rapidly and students become accurate decoders even in reading complex pseudowords by the end of the first grade (Oney \& Durgunoglu, 1997; Oney \& Goldman, 1984). Some Turkish students, however, display reading fluency problems and reading errors during the elementary school years (Bay, 2010; Guzel-Ozmen \& Dogan, 2009; Sahin Inci, Turan, \& Apak, 2006; Yilmaz, 2008) resulting from factors such as limited reading practices, negative attitudes towards reading, and inefficient learning activities or learning disabilities (Akyol \& Temur, 2008; Erden et al., 2002; Guzel-Ozmen \& Dogan, 2009). Hence it is safe to conclude that effective interventions should be identified to optimize Turkish students' reading fluency and reading accuracy.

Several models of reading development suggest that fluency is a one of the most important components of effective reading (Stahl, 2004). Fluent reading is defined as the ability to orally read quickly, accurately, and with proper expression (National Reading Panel, 2000). Some students, particularly students with reading problems, take considerably longer to develop reading fluency. Various intervention strategies have been developed and studied in an attempt to improve reading fluency particularly for poor and disabled readers. These strategies are generally grouped into two broad categories: skill-based and performance-based interventions. Skill-based interventions typically include various antecedent teaching strategies such as listening passage preview (modeling), repeated readings and error correction whereas performance-based interventions involve the manipulation of consequences including performance feedback and contingent reinforcement (Chafouleas, Martens, Dobson, Weinstein, \& Gardner, 2004; Eckert, Ardoin, Daly, \& Martens, 2002). 
In general, skill-based interventions are implemented as a single or combined strategy for improving reading fluency. One of the skill-based interventions, listening passage preview involves someone reading the passage to student while the student read silently (Hale, Skinner, Winn, Oliver, \& Allin, \& Molloy, 2005). Research have suggested that listening passage preview was effective on improving students' oral reading fluency (Daly \& Martens, 1994; Daly, Martens, Hamler, Dool, \& Eckert, 1999), accuracy (Daly, Martens, Dool, \& Hintze, 1998), and comprehension levels (Dowhower, 1987; Skinner, Robinson, Adamson, Atchison, \& Woodward, 1998). Another skill-based intervention, repeated readings have been most widely used to improve reading fluency (Ardoin, Eckert, \& Cole, 2008; Dowhower, 1987; Herman, 1985; Stoddard, Valacante, Sindelar, O’Shea, \& Algozzine, 1993; Valleley \& Shriver, 2003). Repeated readings require student read orally a passage more than once. Findings from various studies have indicated that repeated readings resulted in increased reading fluency and comprehension skills for variety of populations such as students with learning disabilities and reading difficulties (Ardoin et al., 2008; Begeny, Daly, \& Valleley, 2006; Chard, Vaughn, \& Tyler, 2002; Kuhn \& Stahl 2003; Levy, Nicholls, \& Kohen, 1993; Therrien, 2004; Valleley \& Shriver, 2003; Weinstein \& Cooke, 1992).

Performance feedback and contingent reinforcement are two types of performancebased interventions which have been typically used in combination with skill-based interventions (Chafouleas et al., 2004; Eckert et al., 2002). Performance feedback has been defined as providing students with information regarding their reading behavior (Ysseldyke \& Elliott, 1999) whereas contingent reinforcement involves the provision of reward after student meeting specified criterion for reading rate. Often, these strategies are implemented as either a single strategy or combined strategies in accordance to students' instructional needs.

In recent years, brief experimental analysis (BEA) has emerged as an approach to identify the most effective instructional strategies needed to increase reading fluency before applying an intervention for extended periods of time. The foundation of BEA comes from applied behavior analysis in which functional analysis is used to identify functional or casual relations between behaviors and events surrounding their occurrence (Martens \& Eckert, 2000). Functional analysis implemented through BEA in academic skills conducts brief test conditions to assess a student's response to an intervention condition, and allows for a direct link between assessment and intervention (Martens, Eckert, Bradley, \& Ardoin, 1999). 
BEA has been used as an assessment approach for selecting effective instructional components to determine how to teach poor readers. This analysis has frequently been conducted within brief multielement or alternating treatment design of single subject experimental designs (Daly et al., 1998; Chafouleas et al., 2004). Within brief experimental analysis, student performances have been assessed under baseline and intervention conditions and comparison is then made between interventions and baseline to determine the most effective intervention (Wilber \& Cushman, 2006). The sequential or alternating applications of intervention components are continued until visibly discernible improvements in performance are observed (Eckert, Ardoin, Daisey, \& Scarola, 2000).

In many recent studies, BEA has been used to identify the efficacy of single or combined treatment effects of skill-based interventions (Daly, Murdoch, Lillenstein, Webber, \& Lentz, 2002; VanAuken, Chafouleas, Bradley, \& Martens, 2002) and single and combined treatment effects of skill-based and performance-based interventions in improving oral reading performance student with reading difficulties (Cates, Thomason, Havey, \& McCormick, 2006; Daly et al., 1998; 1999; Eckert et al., 2000; Noell, Freeland, Witt, \& Gansle, 2001). The results of the experimental studies have shown that BEA was effective in identifying effective interventions associated with enhanced academic responding. In addition, studies have repeatedly shown that the combined interventions are generally more effective in improving reading fluency (Daly et al., 1998; Eckert et al., 2000). Yet, many researchers have found that the effects of various interventions may be idiosyncratic across students (Cates et al., 2006; Daly et al., 1998; 2002; Eckert et al., 2000; Noell et al., 2001).

One limitation of the current literature is that only a few investigations were published in the past several decades examining the effects of combined skill-and performance-based interventions on oral reading fluency. For example, Eckert et al. (2002) used alternating treatment designs to examine the effects of listening passage preview and repeated readings alone or in combination with performance feedback, contingent reinforcement, or both. Participants were second and third grade elementary students with reading difficulties. Their findings demonstrated that four of the six participating students gained maximum benefit when combinations of skill-and performance-based strategies were implemented. Another study conducted by Noell et al. (1998) compared the effects of contingent reward alone, contingent reward plus modeling and practice, and modeling and practice alone. The study 
participants were fourth grade students with attention deficit hyperactivity disorder. The results indicated that two participants benefited most when modeling and practice were added to contingent reward, with one participant benefited more from a combination of modeling and practice.

In a later study, Chafouleas et al. (2002) examined the effects of a skill-based intervention alone and in combination with two performance-based interventions on the reading and error rates of three elementary students exhibiting reading problems. Results were differentiated when compared to students' baseline levels. Repeated reading was clearly more effective in increasing the fluency of participants with low reading rates and lowest error rates at the baseline. In contrast, the participant who exhibited the lowest reading rate and highest error rate benefited the most when repeated reading was offered in conjunction with performance feedback or performance feedback plus contingent reward.

Studies examining the effectiveness of BEA in identifying effective interventions are limited in Turkey. To date only two studies have been conducted to assess the utility of BEA in increasing reading fluency of elementary students with intellectual disability (GuzelOzmen \& Cevik, 2005; Orcan \& Guzel-Ozmen, 2010). In an earlier study, Guzel-Ozmen and Cevik (2005) compared to the effects of listening passage preview and repeated readings alone or in combination with performance feedback, or two performance-based interventions. They found that the combinations of skill-and performance-based interventions were effective for two of the four students. The researchers also reported that combination of skill-based intervention was more effective for the remaining two participants. A more recent study examined the effectiveness of repeated reading alone or in combination with performance feedback, contingent reinforcement, or both (Orcan \& Guzel-Ozmen, 2010). The results indicated that one student benefited most from the repeated reading, while other student benefited more from the combination of repeated reading and performance feedback. These results may suggest that BEA can be successfully used in selecting effective reading interventions for Turkish students.

An important educational issue is whether these research findings can lead to improvements on oral reading fluency of Turkish students with reading difficulties. The available evidence has emerged since 2005 (Guzel-Ozmen \& Cevik, 2005; Orcan \& GuzelOzmen, 2010), but it is very limited. Even though these studies highlighted the effectiveness 
of combined skill-and performance-based interventions on oral reading fluency in Turkish, there is a further need to investigate the effectiveness of these combined interventions in Turkish students with reading difficulties. Thus, even though available studies highlighted the effectiveness of combined skill-and performance-based interventions on oral reading fluency in Turkish, there is a further need to investigate the effectiveness of these combined interventions in Turkish students with reading difficulties. Thus, the purpose of this study was to explore the effects of adding performance feedback to skill based interventions on improving oral reading fluency of Turkish students with reading difficulties. For this purpose, three different combined intervention packages were implemented in the study. These packages included Listening Passage Preview and Repeated Reading (LPP+RR), Repeated Reading with Performance Feedback $(\mathrm{RR}+\mathrm{PF})$, and Listening Passage Preview and Repeated Reading with Performance Feedback $(\mathrm{LPP}+\mathrm{RR}+\mathrm{PF})$. This study has importance in two respects: first, the present study replicates and extends the previous research on BEA of reading fluency in Turkish language. Secondly, it examines the relative contribution of strategies by using brief analysis for determining effective intervention package of the reading interventions for Turkish students with reading difficulties.

\section{Method}

\section{Participants and Settings}

Four students with reading difficulties participated in the study. Participants were selected from regular education classrooms in a public elementary school serving students in kindergarten through eighth grade in Ankara, capital city of Turkey. In order to select participating students, structured interviews were conducted with teachers from the second to fifth grade to identify the students with reading difficulties. A total of eight students were referred by their teachers due to displaying reading difficulties. Participants were selected through following criteria: (1) decoded correctly at least $90 \%$ of the selected texts, and (2) had slow reading rate, defined by the number of words read correctly per minute (WRCM) (i.e., a reading rate of at least $30 \%$ below of published norms for the elementary grade levels. Previous research findings were used to guide the identification of study participants and compare the results with published norms for the second criterion. According to one published norm, Turkish students read approximately 71.13 WRCM by the end of the second 
grade, 91.46 WRCM by the end of the third grade, 97.07 WRCM by the end of the fourth grade, and approximately 120.76 WRCM by the end of the fifth grade (Erden et al., 2002).

Initially, a screening was carried out by the researcher using the passages form second to fifth grade to assess students' reading fluency and accuracy prior to the participation in the study. The students' reading fluency and accuracy levels have been determined with a story whose features were explained in the material section and had also been validated by area experts. These stories were selected based on candidate students' grade level. Students' performances were scored as WRCM and errors in the whole text. An observer also recorded the students' fluency and accuracy performance. Of the eight students screened, four students met the study inclusion criteria. The other four students were not selected as study participants because their WRCM scores were observed to be higher among the study candidates according to the published norms.

The four participants were all males whose native language was Turkish. Three of them were fourth grade students ranged in age from 9 years 6 months to 9 years 10 months. The fourth student was attending a third grade classroom and his age was 8 years and 5 months. None of the students were receiving any academic assistance in the area of reading outside of traditional reading instruction in their general education classrooms at the time of the study. A parental consent and student assent were obtained for each student before conducting the study.

BEA occurred individually in a room used specifically for tutoring. The room was equipped with a table and two chairs. An audiotape was used to record the sessions for interscorer agreement and procedural integrity.

\section{Materials}

Passages. Instructional passages were selected randomly from three third and four fourth grade Turkish language text books. For each grade level, a total of 18 narrative passages were selected as study materials. The passages were composed of single stories and each was written on a single or double pages. It is important to note that passage readability level was not measured during the study because a readability formula was not available in Turkish language. Following the selection of the passages, the passages were examined by 
four area experts. Two experts were faculty members of Turkish language department of a university and the remaining two were elementary school teachers. A Likert-type scale was prepared for these experts to review the compliance of the selected passages to the grade levels of the students. The Likert-type scale included items reflecting linguistic compliance, length of words, length of sentences, and content compliance. The scale items were all ranged from strongly agree (5) to strongly disagree (1). The experts were given the selected passages and the Likert-type scale. All experts were asked to rate the compliance of each passage to the grade level. The passages selected for the study were rated by the experts. Only passages which were rated greater or equal to 4.0 were included in the study. For each grade level, among 18 passages reviewed by the reviewers, 15 were rated greater or equal to 4.0. Of the 15 passages, 13 were selected in order to provide student different reading passages in each experimental session. A total of 26 narrative passages were used in the study. The fourth grade average passage length was 203 words (range, 147 to 264) whereas the third grade average passage length was 137 words (range, 105 to174). Each passage was typed and did not include any pictures. All instructional passages were randomly chosen across all experimental sessions.

Performance feedback bar graphs. In order to display students' reading performance, two performance feedback bar graphs were developed for the $\mathrm{RR}+\mathrm{PF}$ and $\mathrm{LPP}+\mathrm{RR}+\mathrm{PF}$ conditions. Each bar graph had three columns to record student's reading performance in the first, second, and third readings. The first graph was used to record the reading time in which the student read entire passage. The second graph was used to record the number of errors in whole text.

\section{Experimental Design and Procedures}

BEA of oral reading fluency was conducted using an alternating treatment design. Alternating treatment design allows the comparisons of treatment conditions within a single subject framework and provides useful data in determining the most effective treatment condition. With the alternating treatment design, interventions are rapidly alternated and randomly assigned to each experimental session across all participants (Tawney \& Gast, 1984). In this study too, all intervention conditions and baseline conditions were applied in a randomized order, with each condition occurring three times for each student. The 
interventions were rapidly alternated by applying two interventions in each intervention day. Fifty-minute breaks were given between the intervention sessions.

Four experimental conditions were applied in the study: Baseline (BL), the LPP+RR, $\mathrm{RR}+\mathrm{PF}$, and $\mathrm{LPP}+\mathrm{RR}+\mathrm{PF}$. All experimental conditions were conducted by the researcher in school days. Each intervention session lasted approximately 25 minutes. The experimental process was completed in a total of five weeks.

The following conditions were in effect during the experiment:

$B L$. During the baseline condition, no instructional intervention was implemented. For the assessment purposes in this phase, the researcher instructed the student to read aloud the entire passage with his best reading. Student's reading errors were recorded on a researcher copy of the passage until the end of the first minute.

$L P P+R R$. This condition involved the researcher reading the passage to the student at a comfortable reading rate while the student followed the passage. Next, the researcher instructed the student to read the passage three times with his best reading. The student then read aloud the passage three times while the researcher marked the student's errors during the first minute of the last reading of the passage.

$R R+P F$. This condition involved the researcher instructing the student to read a selected passage three times and to record his reading time and number of errors in the whole text on bar graphs. Performance feedback was presented using following procedures: before beginning the first reading, the researcher explained the student how to record his reading time and number of errors on the bar graph. Next, the researcher instructed the student to read the entire passage aloud with his best reading. The researcher then started stopwatch and marked the errors made by the student on the entire passage. When the student completed the reading, the researcher informed the student about his reading time and number of the errors that he made. The researcher then recorded his performance on the corresponding bar graphs. Before the second time of the reading, the researcher encouraged the student to try to decrease his reading time and number of errors. Identical procedures described above were used during the second reading. After the second reading, the researcher pointed out the differences between the student's first and second reading performances on the bar graphs. If the 
student's reading time and number of errors decreased, the researcher told the student "You read the passage in less time than your first reading and made fewer errors. Great job." If the reading rate and number of errors did not decrease, then the researcher told the student to try to decrease his reading time and number or errors for the third reading. For the third reading, the researcher identified reading goals, which presented both $\% 3$ and $\% 5$ improvements (Eckert et al., 2002; Guzel-Ozmen \& Cevik, 2005) in performance over the second reading for the participant to select. In order to determine the reading rate goals, first $3 \%$ and $5 \%$ of the student's reading time of full passage in the second reading were calculated. Second, obtained result was subtracted from the total reading time of the full passage achieved in the second reading. The same process was also applied to the calculation of reading errors. These reading goals were also inserted on the graphs before the last reading. When the student completed the last reading, the researcher recorded the student's performance on the graphs. The student was informed about whether he reached his reading goals or not.

$L P P+R R+P F$. This condition involved the researcher reading the selected passage to the student at a comfortable reading rate while the student followed the passage. Then identical procedures used in the RR+PF conditions were applied.

\section{Dependent Variable and Data collection}

The dependent variable of this study was WRCM. Words read correctly per minute were calculated by subtracting the number of errors from the total number of words attempted within the first minute period. Data were collected from initial minute of the first reading during the baseline condition. During the other three intervention conditions, the student read the passage three times, and the first minute of the last reading was used for data collection purposes.

Each reading session was audiotaped by the researcher across all four conditions. In each session, the student was asked to read the entire passage aloud with his best reading while the researcher followed on a copy of the passage. As soon as the student read the first word in the passage, the researcher started the stopwatch. The researcher recorded the student reading errors and marked the word the student read at the end of the one minute. If the student skipped an entire line of text, the researcher showed the skipped line and asked the student continue reading. If the student struggled to pronounce a word or hesitated for 3 
seconds, then the researcher provided the word immediately and asked to student to continue reading.

In scoring, a word was scored as correct if the student accurately pronounced the word within 3 seconds (Shinn, 1989). Repetitions and self-corrections of a word in 3 seconds were scored as correct as well (Shinn). Errors included mispronunciations, omissions, and hesitations of a word more than 3 seconds (Shinn). Inserted words that were not part of the text were not counted as correct words.

\section{Data Analysis}

Data for the reading rate were analyzed through visual inspection of the data. Three criteria were used to identify the most effective strategy combination. First, the intervention that resulted in a student meeting the published norms was considered to be an effective intervention. According to the published norms, Turkish students read approximately 91.46 WRCM by the end of the third grade, and approximately 97.07 WRCM by the end of the fourth grade (Erden et al., 2002). Since it was possible that none of the interventions would result in meeting these effectiveness criteria or multiple interventions would result in meeting the same criteria, two additional criteria were developed by the researcher. The second criterion included data trend, and the third criterion consisted the level of data path. In single subject designs, study data are typically analyzed based on data trend and level of data path (Tawney \& Gast, 1984). According to Tawney \& Gast (1984), an intervention that results in the steepest increasing trend or higher data level must be considered as the most effective intervention in the case of a behavior that needs improvement. If data gathered from two interventions show an increasing trend or lack a discernable trend, then the third criterion was utilized. The intervention that resulted in the highest level of performance in one session when compared to other interventions was considered to be the most effective intervention. However, if the obtained level difference in the study data were less than $5 \%$ between the two interventions, then both interventions were considered to be equally effective from an educational standpoint (Cates et al., 2006). 
Interscorer agreement data were collected during 4 (30\%) sessions across all conditions including each participant, respectively. A senior student in special education department who was also blind to the experimental conditions and the assessment results was trained in scoring reading fluency data. A copy of the passages used in the study and audiocassettes of the experimental conditions were given to the student. The student was asked to listen to the audiocassettes and record the correct and incorrect words read by the participants in one minute. Interscorer agreement scores were calculated by comparing observer and researcher's recordings of the correct and incorrect responses.

An agreement was counted if both the researcher and the senior student marked the same word as correct or incorrect. A disagreement was counted if the senior student's marking differed from those of the researcher. Percentage of the agreements was calculated by dividing the number of agreements plus disagreements and multiplying by $100 \%$ (House, House, \& Campbell, 1981). Mean interscorer agreement for each student on correct words and errors in one minute was $100 \%$.

To determine the procedural integrity, instructional procedures were written for each intervention condition. Each step of the instructional procedures was formed as a checklist. A checklist was developed for each experimental condition. These checklists included implementation steps of each intervention. The senior student in special education department rated the researcher's procedural integrity using these checklists. The senior student listened to 4 audiocassette recordings (30\%) of the 13 experimental sessions including each intervention condition for each participant, respectively. The senior student placed a check mark next to each step completed during a session. Integrity of the experimental procedures was computed by dividing the number of steps the researcher implemented by the total number of steps listed, which was then multiplied by 100. Across all participants procedural integrity was $100 \%$.

\section{Results}

As shown in Figure 1, increases in the number of WRCM by all participants were observed following the presentation of all intervention conditions relative to the baseline. 
However there were some individual differences across participants in their reading fluency levels relative to the intervention conditions. See the Figure 1.

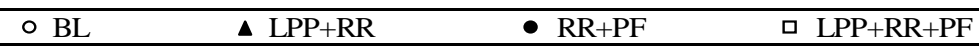

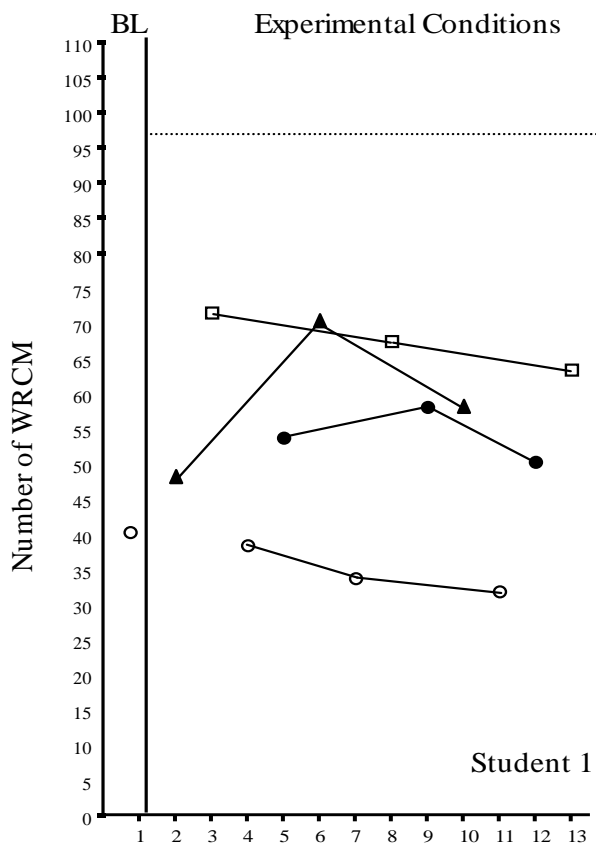

Sessions

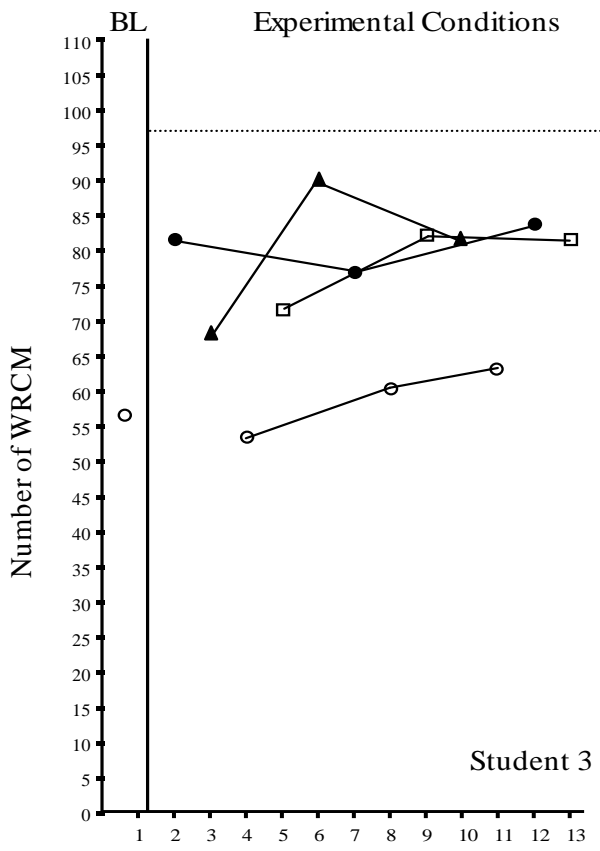

Sessions

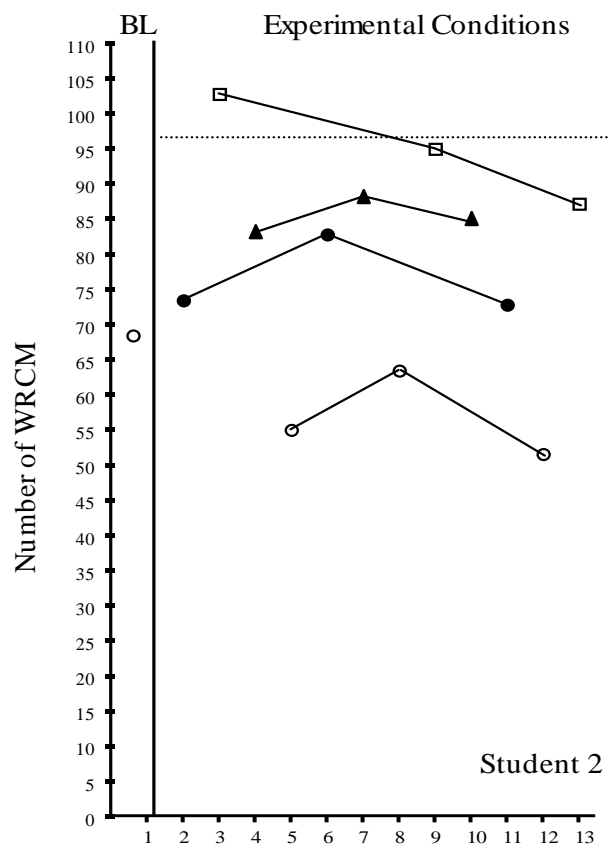

Sessions

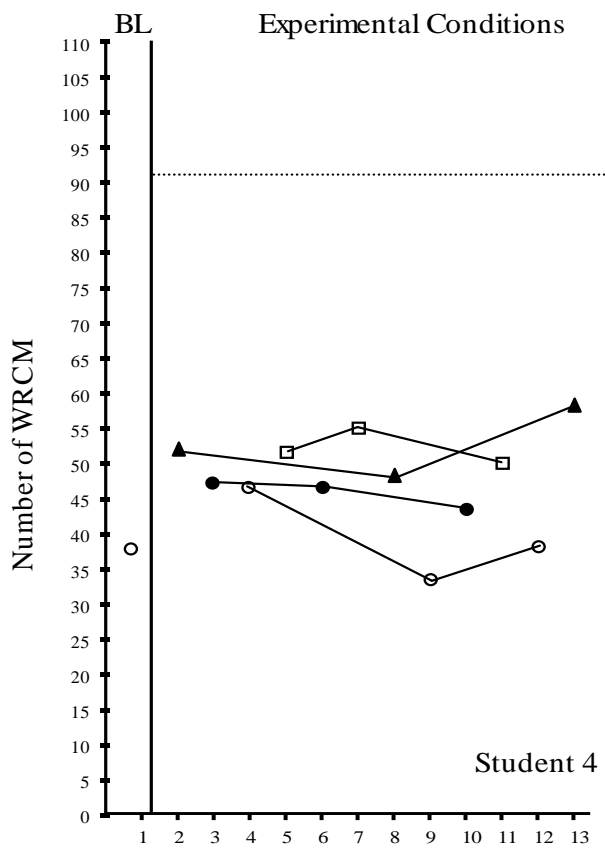

Sessions

Figure 1. Number of Words Read Per Minute Across Experimental Conditions for Each Participant. 
The first student's WRCM score was below the target criterion (97.07 WRCM) in all combined conditions. However, the first student exceeded baseline rates in all intervention conditions. The first student demonstrated variable performance in the LPP+RR condition. Despite the results showing an increasing data trend from the first to second session in the LPP+RR condition, this trend was decreased in the last session. A slightly decreasing trend was observed in the LPP $+\mathrm{RR}+\mathrm{PF}$ condition, but the student's level of data was higher than the other two combined conditions in two of three sessions. Overall, the first student had the highest WRCM score in the LPP+RR+PF condition. Therefore, the $\mathrm{LPP}+\mathrm{RR}+\mathrm{PF}$ was the most effective intervention for the first student.

The second student did not meet the target criterion (97.07 WRCM) in the LPP+RR and $\mathrm{RR}+\mathrm{PF}$ conditions but he displayed an observable increase in his oral reading fluency in the $\mathrm{LPP}+\mathrm{RR}$ and $\mathrm{RR}+\mathrm{PF}$ conditions, relative to the baseline. The second student demonstrated a higher performance on the target criterion in the $\mathrm{LPP}+\mathrm{RR}+\mathrm{PF}$ condition during one of the three sessions. Although the $\mathrm{LPP}+\mathrm{RR}+\mathrm{PF}$ condition resulted in increasing trend, the student's level of data was higher than all conditions. Therefore, the most effective intervention was the $\mathrm{LPP}+\mathrm{RR}+\mathrm{PF}$ for the second student.

The third student did not meet target criteria (97.07 WRCM) in none of the conditions. Intervention trends were varied during all intervention conditions. The student read 90 WRCM in the second sessions of the LPP+RR condition which was the highest data across the all conditions. However, he nearly met the study criterion in this session. His score was also differentiated more than $\% 5$ relative to his other combined conditions' scores. Therefore, the most effective intervention was the LPP+RR for the third student

The fourth student demonstrated similar performance in all combined condition. None of the combined conditions resulted in performance meeting the target criterion (91.46 WRCM). The student's data trends were slightly decreased from the second session to the third session of the $\mathrm{RR}+\mathrm{PF}$ and $\mathrm{LPP}+\mathrm{RR}+\mathrm{PF}$ conditions. Only an increasing trend was observed the second to the third session of the LPP $+\mathrm{RR}$ condition. In addition, the student's highest single performance recorded during the third session of the LPP+RR condition. His score was also differentiated more than $\% 5$ relative to his other two combined conditions' scores. Therefore, the most effective intervention was the LPP+RR for the fourth student. 


\section{Discussion}

The purpose of this study was to investigate the effects of adding a performance feedback to skill based interventions on improving oral reading fluency of Turkish students with reading difficulties. Study results showed that two participants' reading fluency improved as a function of the $\mathrm{LPP}+\mathrm{RR}+\mathrm{PF}$ intervention and remaining two participants had the highest scores in the LPP+RR condition.

The findings of the current study support and expand earlier research in two important ways. First, similar to previous studies in this area (Chafouleas et al., 2004; Eckert et al., $2000 ; 2002)$, this study supported combined effectiveness of the LPP+RR+PF. Second, consistent with previous studies (Cates et al., 2006; Daly et al., 1998; 2002; Eckert et al., 2000; Noell et al., 2001), the present study found that relative efficacy of combined interventions was idiosyncratic across participating students with reading difficulties.

The analysis of the results revealed that all participants demonstrated improved oral reading performance over their baseline scores in all combined conditions. However, the findings indicated none of the participating students, except the second student, met the study criteria during the combined condition sessions. Among the four students, only the second student reached the study criterion in the $\mathrm{LPP}+\mathrm{RR}+\mathrm{PF}$ condition for one of three intervention sessions. One main reason for the students not to reach study criteria might be their low levels of baseline performance. In fact, the second student who had the highest baseline performance was the only student who met the study criterion. The second reason might be the passage readability level. The passage readability level might have been difficult for students who had lower reading levels. Even though expert review was gathered for the compliance of the passages to students' grade levels, differentiation in the passage difficulty levels might have influenced the study results.

The fourth student demonstrated similar improvements under the $R R+P F, L P P+R R$ and LPP+RR+PF conditions. However, it should be noted that his improvements were lower than other students' improvements. This result may be explained by the repetitive reading (reading a word with the former one read) of the student. It is possible that the fourth student spent more time on reading by repeating the word read before and that may have suppressed potential intervention effects for the combined conditions. 
All participants, except the third participant demonstrated low reading rate performance in the $\mathrm{RR}+\mathrm{PF}$ condition as compared to the other intervention conditions. These results showed that the RR should be provided with the LPP in order to improve students' reading fluency. There are several possible reasons for these intervention effects. First, research suggests that the LLP is an effective strategy to improve students' reading comprehension (Dowhower, 1987; Hale et al., 2005; Skinner et al., 1998). Listening passage from the researcher may have increased students' reading comprehension and improved comprehension probably contributed to the students' reading fluency. Second, major characteristics of Turkish language including systematic letter phoneme correspondences may have an effect on students' improved fluency in the LPP condition. In this condition, student follows silently as an accomplished reader reads a passage aloud at a comfortable reading rate. It is possible that modeling students how to read in a language with a systematic letterphoneme correspondence contributed the effectiveness of the combined conditions. Even though the magnitude of these gains differed across participants and conditions, this study suggest that adding a LPP condition to a combined condition may increase Turkish students' reading fluency.

An important issue in the current study was to determine whether these interventions could cause generalization effects. Results showed that there was no increase in reading fluency of the participants during the baseline conditions. Only the third participant's baseline WRCM score slightly increased at the baseline conditions, however his data level at the baseline was lower than all intervention conditions. These slight increases recorded during the baseline conditions may be related to the nature of the interventions or variables outside the experiment. Overall the findings from the study indicated that instruction effect did not lead to a generalization effect in the baseline data.

When interpreting these results, several limitations should be considered. First, the small sample size limits generalizability of the conclusions that can be drawn from the study. Therefore, the results need to be replicated with experimental studies using large samples of students with reading difficulties in Turkish language. In future studies, the effectiveness of the combined interventions should also be evaluated with students with higher fluency and low accuracy levels. Second, the limited number of instructional strategies was implemented in the study. Additional combinations of skill- and/or performance-based instructional packages should be investigated. Third, the generalized effects of the results were not 
examined with an extended analysis. An extended analysis of the intervention conditions would have increased the reliability of the findings.

In conclusion, the results of this study extend the previous research by examining the effects of the combined intervention packages in improving reading fluency in Turkish language. Findings from the study suggest that assessing relative contribution of the strategies by using brief analysis can help determine the effective intervention packages for Turkish students in improving their reading fluency. Further research should examine the utility of different combinations of skill- and performance-based interventions on students' reading fluency in different languages.

\section{References}

Akyol H., \& Temur, T. (2008). Ses temelli cumle yontemi ve cumle yontemi ile okuma yazma ogrenen ogrencilerin okuma becerilerinin ogretmen goruslerine gore degerlendiril- mesi [Comparing reading skills of first grade students who learn reading-writing with sound-based clause method and clause method]. Mustafa Kemal Universitesi Sosyal Bilimler Enstitusu Dergisi, 5, 78-95.

Ardoin, S. P., Eckert, T. L., \& Cole, C. A. S. (2008). Promoting generalization of reading: A comparison of two fluency-based interventions for improving general education student's oral reading rate. Journal of Behavioral Education, 17, 237-252.

Bay, Y. (2010). Ses temelli cumle yontemiyle ilk okuma-yazma ogretiminin degerlendirilmesi [The evaluation of early reading and writing teaching with phoneme-based sentence]. Kuramsal Egitimbilim, 3, 164-181.

Begeny, J.C., Dally, E. J., \& Valleley, R. J. (2006). Improving oral reading fluency through response opportunities: A comparison of phrase drill error correction with repeated readings. Journal of Behavior Education, 15, 229-235.

Cates, G. L., Thomason, K., Havey, M., \& McCormick, C. (2006). A preliminary investigation of the effects of reading fluency interventions on comprehension: Using brief experimental analysis to select reading interventions. Journal of Applied School Psychology, $23,133-154$. 
Chafouleas, S. M., Martens, B. K., Dobson R. L., Weinstein, K. S., \& Gardner, K. B. (2004). Fluent reading as the improvement of stimulus control: Additive effects of performance-based interventions to repeated reading on students' reading and error rates. Journal of Behavioral Education, 13, 67-81.

Chard, D. J., Vaughn, S., \& Tyler, B. J. (2002). A synthesis of research on effective interventions for building reading fluency with elementary students with learning disabilities. Journal of Learning Disabilities, 35, 386-406.

Daly, E. J., \& Martens, B. K. (1994). A comparison of three interventions for increasing oral reading performance application of the instructional hierarchy. Journal of Applied Behavior Analysis, 27, 459-469.

Daly, E. J., Martens, B. K., Dool, E. J., \& Hintze, J. M. (1998). Using brief functional analysis to select interventions for oral reading. Journal of Behavioral Education, 8, 203-218.

Daly, E. J., Martens, B. K., Hamler, K. R., Dool, E. J., \& Eckert, T. L. (1999). A brief experimental analysis for identifying instructional components needed to improve oral reading fluency. Journal of Applied Behavior Analysis, 32, 83-94.

Daly, E. J., Murdoch, A., Lillenstein, L., Webber, L., \& Lentz, F. E. (2002). An examination of methods for testing treatments: Conducting brief experimental analyses of the effects of instructional components on oral reading fluency. Education and Treatment of Children, 25, 288-316.

Dowhower, S. L. (1987). Effects of repeated reading on second-grade transitional reader's fluency and comprehension. Reading Research Quarterly, 22, 389-406.

Eckert, T. L., Ardoin, S. P., Daisey, D. M., \& Scarola, M. D. (2000). Empirically evaluating the effectiveness of reading interventions: The use of brief experimental analysis and single case designs. Psychology in the Schools, 37, 463-473.

Eckert, T. L., Ardoin, S. P., Daly, E. J., \& Martens, B. K. (2002). Improving oral reading fluency: A brief experimental analysis of combining an antecedent intervention with consequences. Journal of Applied Behavior Analysis, 35, 271-281. 
Erden, G. Kurdoğlu, F., \& Uslu, R. (2002). Development of grade level norms for reading speed and writing errors of Turkish elementary school children. Journal of Turkish Psychiatry, 13, 5-13.

Farr, R. C., \& Carey, R. F. (1986). Reading: What can be measured? (2nd ed.), Newark, DE: International Reading Association.

Fuchs, L. S., Fuchs, D., Hosp, M. K., \& Jenkins, J. R. (2001). Oral reading fluency as an indicator of reading competence: A theoretical, empirical, and historical analysis. Scientific Studies of Reading, 5, 239-256.

Guzel-Ozmen, R., \& Cevik, G. (2005). The effectiveness of antecedent and consequence interventions using combined and separated formats in oral reading fluency . In G. Shiel, I. Stricevic, \& D. Sabolovic-Krajina (Eds.), 14th European conference on reading, Croatia (pp 243-249). Retrieved from www.hcd.hr/datoteke/ Zagreb_Conference_Proceedings.pdf.

Guzel-Ozmen, R., \& Dogan, Y. (2009, July). Illk okuma yazmayi farkll yontemlerle ogrenen ogrencilerin okudugunu anlama, okuma hizi ve okuma hatalari bakımından karsilastirilmasi [Comparison to reading comprehension, oral reading rate and reading mistake of elementary students in terms of acquisition reading different literacy instruction method]. Paper presented at the meeting of the Second International Turkish Teaching and Education Congress, Urgup, Turkey.

Hale, A. D., Skinner, C. H., Winn, B. D., Oliver, R., Allin, J. D., \& Molloy, C. C. M. (2005). An investigation of listening and listening-while-reading accommodations on reading comprehension levels and rates in students with emotional disorders. Psychology in the Schools, 42, 39-51.

Herman, P. A. (1985). The effect of repeated readings on reading rate, speech pauses, and word recognition. Reading Research Quarterly, 20, 553-565.

Hopewell, K. McLaughlin, T. F., \& Derby, K.M. (2011). The Effects of reading racetrack with direct instruction flashcards and token system on sight word acquisition for two 
primary students with severe conduct disorders. Electronic Journal of Research Educational Psychology, 9, 693-710.

House, A.W., House, B.G., \& Campbell, M. B. (1981). Measures of interobserver agreement: Calculation formula and distribution effect. Journal of Behavioral Assessment, 3, 37 57.

Lipson, M. Y., \& Lang, L. B. (1991). Not as easy as it seems: Some unresolved questions about fluency. Theory Into Practice, 30, 218-227.

Kuhn, M. R., \& Stahl, S. A. (2003). Fluency: A review of developmental and remedial practices. Journal of Educational Psychology, 95, 3-21.

Levy, B. A., Nicholls, A., \& Kohen, D. (1993). Repeated readings: Process benefits for good and poor readers. Journal of Experimental Child Psychology, 56, 303-327.

Martens, B. K., \& Eckert, T. L. (2000). The essential role of data in psychological theory. Journal of School Psychology, 38, 369-376.

Martens, B. K., Eckert, T. L., Bradley, T. A., \& Ardoin, S. P. (1999). Identifying effective treatments from a brief experimental analysis: Using single-case design elements to aid decision making. School Psychology Quarterly, 38, 369-376.

National Reading Panel. (2000). Report of the National Reading Panel teaching children to read: An evidence-based assessment of the scientific research literature on reading and its implications for reading instruction. Washington, DC: National Academy Press.

Noell, G. H., Freeland, J. T., Witt, J. C., \& Gansle, K. A. (2001). Using brief assessments to identify effective interventions for individual students. Journal of School Psychology, 39, 335-355.

Noell, G. H., Gansle, K. A., Witt, J. C., Whitmarsh, E. L., Freeland, J. T., LaFleur, L. H., Gilbertons, D. N., \& Northup, J. (1998). Effects of contingent reward and instruction on oral reading performance at differing levels of passage difficult. Journal of Applied Behavior Analysis, 31, 659-663.

Orcan, M., \& Guzel-Ozmen, R. (2010). (2010, October). Zihinsel yetersizlikten etkilenmis og- 
rencilerin okuma hizinin artirilmasinda sagaltim paketlerinden etkili olanın belirlenmesi (Klsa deneysel analiz ve genisletilmis analiz calismasi) [Determining of effective intervention packages for improving reading fluency in students with intellectual disability (A brief experimental analysis and extended analysis study)]. Paper presented at the meeting of the $20^{\text {th }}$. National Special Education Congress, Gaziantep, Turkey.

Reschly, A. L., Busch, T. W., Betts, J., Deno, S. L., \& Long, J. D. (2009). Curriculum-Based measurement oral reading as an indicator of reading achievement: A meta-analysis of the corelational evidence. Journal of School Psychology, 47, 427- 469.

Roldán, R. M. M., Segura, F. P., \& Roldán, A. M. M. (2003). Improvement in reading processes through the MATEL program. Electronic Journal of Research Educational Psychology, 1, 137-153.

Sahin, I., Inci, S., Turan, H., \& Apak, O. (2006). Ilk okuma ogretiminde ses temelli cumle yontemiyle cozumleme yonteminin karsilastirilmasi [Comparison of the phonics and the whole language methods on reading instruction]. Milli Egitim Dergisi 171,

Shinn, M. R. (1989). Curriculum-based measurement: Assessing special children. New York: Guilford Press.

Shinn, M. R., Good, R. H., Knutson, N., Tilly, G., \& Collins, V. L. (1992). Curriculum-based measurement reading fluency: A confirmatory analysis of its relation to reading. School Psychology Review, 21, 459-479.

Skinner, C. H., Robinson, D. H., Adamson, K. L., Atchison, L. A., \& Woodward, J. R. (1998). Effects of different listening-while-reading rates on comprehension in secondary students with reading deficits. Special Services in the Schools, 13, 115-128.

Stahl, S. A. (2004). What do we know about fluency? In P. McCardle, \& V. Chhabra (Eds.) The voice of evidence in reading research (pp.187-211). Maryland: Paul H. Brookes Publishing.

Stoddard, K., Valacante, G., Sindelar, P., O’Shea, L., \& Algozzine, B. (1993). Increasing reading rate and comprehension: the effects of repeated readings, sentence segmenta- 
tion, and intonation training. Reading Research and Instruction, 32, 53-65.

Tawney, J. W., \& Gast, D. L. (1984). Single subject research in special education. Ohio: A Bell and Howell Company.

Therrien, W. J. (2004). Fluency and comprehension gains as a result of repeated reading: A meta-analysis. Remedial and Special Education, 25, 252-261.

Tindal, G. A., \& Marston, D. B. (1990). Classroom-based assessment: Evaluating instructional outcomes. Columbus, $\mathrm{OH}$ : Merrill.

VanAuken, T. L., Chafouleas, S. M., Bradley, T. A., \& Martens, B. K. (2002). Using brief experimental analysis to select oral reading interventions: An investigation of treatment utility. Journal of Behavioral Education, 11, 163-179.

Weinstein, G., \& Cooke, N. L. (1992). The effects of two repeated reading interventions on generalization of fluency. Learning Disability Quarterly, 15, 21-28.

Wilber, A., \& Cushman, T. P. (2006). Selecting effective academic interventions: an example using brief experimental analysis for oral reading. Psychology in the Schools, 43, 79-84.

Valleley, R J. \& Shriver, M.D. (2003) An Examination of the effects of repeated readings with secondary students. Journal of Behavioral Education, 12, 55-76.

Yilmaz, M. (2008). Kelime tekrar tekniginin akici okuma becerilerini gelistirmeye etkisi [The effect of word drill technique on improving fluently reading of skills]. Turk Egitim Bilimleri Dergisi, 2, 323-350.

Ysseldyke, J. E., \& Elliott, J. (1999). Effective instructional practices: Implications for Assessing Educational Environments. In C. Reynolds \& T. Gutkin (Eds.), The Handbook of School Psychology, (pp, 497-518). New York: John Wiley \& Sons, Inc. 